\title{
Quality of Indian service industries with different ANN models
}

\author{
Ajay Behera a $^{*}$ \\ CH R O N I C L E \\ Article history: \\ Received: June 18, 2018 \\ Received in revised format: July \\ 22, 2019 \\ Accepted: September 3, 2019 \\ Available online: September 5, \\ 2019 \\ Keywords: \\ Service Quality \\ Artificial Neural Network (ANN) \\ Feed Forward Neural Networks \\ (FNNs) \\ Recurrent Neural Networks \\ $(R N N s)$ \\ Total Quality Management (TQM) \\ Service Sectors
}

${ }^{a}$ ITER, SOA University, Bhubaneswar, India

\section{A B S T R A C T}

\begin{abstract}
Service quality is basically a comparison between expectations and the perceptions of the customer. The interrelationship between various aspects of information technology (IT) adoption and other basic characteristics of service quality is complex and dependent on the expected service composition. Reliability, conformance, durability and serviceability are taken as functions of service quality; whereas Tenure, utility and vendor are taken as functions of Information Technology. Substantial literature has examined the concept of service quality, its dimensions, and measurement methods. Statistical analysis of quality parameters has been performed and validation is done with different Artificial Neural Network (ANNs) architecture with different hidden layers. The model proposed in this study is designed to evaluate and improve service quality within a comprehensive framework.
\end{abstract}

\section{Introduction}

All through the world business firms are engaged with assembling of items or conveying administration or both perceive quality and execution as two contending factors either to enhance or keep up or recapture their piece of the pie. To viably control and oversee quality and execution ventures are thinking about on improvement of inventive ways and means utilizing quality administration standards with a view to plan techniques and strategies to interest the magnificence. Any business firm may endeavor to distinguish client necessities and deliver the correct quality merchandise/administrations to energize the clients despite the fact that the points and objectives of a business may contrast. Old practices of value control and assessment exercises have been supplanted or supplemented by quality confirmation since 1970s and by and by, add up to quality administration (TQM) is earnestly honed in numerous associations (Dale,1999). Prior routine with regards to quality administration varies in two particular elements from TQM: (i) rather than basically concentrating on parts of the item or administration it grasps the entire association; (ii)

\footnotetext{
* Corresponding author.

E-mail address: mail2ajaybehera@yahoo.co.in (A. Behera) 
instead of concentrating on extensive venture on resources it achieves social change in the association. In created nations over $75 \%$ of the GDP is contributed by benefit areas and right now, in the vast majority of the creating nations a similar pattern is being watched (Mitra, 2003). Be that as it may, it is intriguing pattern that just a single fifth of the examination articles are identified with benefit segment out of the aggregate number of articles considered the extent that exploration identified with TQM and its execution design is concerned, both in assembling and administration segment. As behavioral angles are engaged with conveying administration, low rate of appropriation of TQM standards in benefit division might be credited. In a hierarchical setting desires and impression of clients are to a great extent affected by two critical parts of TQM usage (estimation and assessment of administration quality) since they are straightforwardly engaged with the procedure of conveyance of administration. What's more, benefit quality is incredibly impacted by sort and size of administration setting and interior and outside components of the association.

A service system consisting of a series of processing stages with information flow provides variety of services as and when required. Service systems are confronted with new pressures in evolving service environment to offer customized services with timely delivery, high quality and more performance (Cui et al., 2003). In addition, IT adopted service system has contributed towards improvement in market share and ability to handle various services (Dewhurst et al., 2003). IT Demand has increased with the development of high bandwidth telecommunications networking and database systems that allow businesses to operate in a global way (Ghobakhloo at al., 2011). Overall quality of service system depends on many factors (Chang, 2014). During the last few years, IT adoption has generated a milestone in banking transactions through the increased use of ATMs in developing countries like India (KPMG, 2015). Measurement and evaluation standards and procedures for quality of service systems have become practically inconvenient (Tanriverdi, 2005). For systematic assessment of quality, it is desirable to develop a comprehensive methodology to enable the managers and academicians to design an instrument consisting of service quality dimensions and its related items (Yan et al., 2006). However, researchers have noted that studies on barriers to adoption have been conducted in developed countries (Behera et al., 2015a). A typical service system needs to be developed incorporating several IT adoption tools and techniques to ensure its quality in changing environment and market conditions (Mwangi \& Brown, 2015). Indian banking and software industry have undertaken a number of measures to make ease in various operations (Behera et al., 2015c) In addition, the Indian government has passed legislation covering internet banking services. Despite these efforts, service delivery remains a major barrier due to poor IT adoption (Behera et al., 2015b). In response to the concerns of Indian banks and software firm, this research presents a development and empirical testing of a model that links the perceived level of performance of service delivery systems to IT adoption (Chen et al., 2012). The objective of this study is to examine the role of tenure, utility and vendor on IT adoption and ultimately its role on quality of service delivery system. As the pace of development and adoption of new technologies varies between service firms, the type of service is likely to influence the extent of IT adoption. In the following sections, we discuss review of literature. We then discuss the methodology, analytical results, conclusions and recommendations of our findings.

\section{Literature Review and Hypotheses}

Previous literature addresses the importance of IT adoption in the quality of service firms. However, a close look at the literature reveals that there is no common agreement among the authors on even the definition of IT adoption, IT adoption equipment, service system design, service quality, and system performance. In the era of e-Banking, IT-based systems are able to handle core-banking functionalities (Peter at al., 2011). Banks are motivated to incorporate IT literacy skills among the existing bank staff to enhance performance (Lepmets et al., 2014). Bank employee with IT knowledge caters banking services as per the customer requirements (Hawari \& Ward, 2006). With the incorporation of IT, there is ample opportunity enabling organizations to succeed financially (Doha et al., 2014). 
Researchers and practitioners have proposed a number of models and methodologies for measuring and evaluating firm quality (Igbaria \& Tan, 1997). Those models address operational and financial aspects (Mikhailov \& Tsvetinov, 2004). Strategies of IT adoption are required to measure system quality (Goo, 2010). The studies on the relationship between IT adoption and Reliability are conducted in either of the two ways: empirically finding out the relationships in a given service system or proposing an analyti$\mathrm{cal} /$ mathematical model of these relationships (Yee et al., 2013). A few investigators have reported empirical relationships between specific IT adoption and quality dimensions (Zhang et al., 2007; Parka et al., 2012). The hypothesis can be formulated as:

$\mathrm{H}_{1}$ : IT adoption has significant positive effect on Reliability.

In service sector, IT adoption process is directly affected by top management where all decisions from daily functions to future investments are made by them. Knowledge and experience of CEO are important factors for affecting IT adoption (Ghobakhloo et al., 2010). The study revealed that, the role of CEOs (top management, owner) affect activities, both in current and in future (Durdyeva et al., 2014; Davis, 1989). The study has found that there is a negative impact on business productivity due to lack of sufficient IT user employees (Southern \& Tilley, 2000). Quality of service system depends upon many factors, namely, level of IT service quality, customer attitude towards IT usage, customer satisfaction, and operational efficiency (Bruque \& Moyano, 2007). Thus, it can be hypothesized as follows:

$\mathrm{H}_{2}$ : IT adoption has significant positive effect on Conformance.

Online finance introduced by bank leverage state of the art technology for the convenience of customers (Jayawardhane, 2004). Online financing has been established under Supply Chain Finance Unit (Shaik and Abdul, 2014). Apart from the traditional banking business, banks have been strengthened to produce variety of financial and non-financial activities (Bergendahl \& Lindblom, 2008). Technological change has been accepted by the Bankers (Arasli, 2005). Automated customer care and self-service are the main cause to reduce costs and handle an ever-increasing number of transactions (Therrien at al., 2011). Due to the changing demand, customers are not dependent on a single communication device (Chan \& Ngai, 2010). In the shifting paradigm, customers can be expected anytime, anywhere access to services (Gustafsson et al., 2003). Thus, the effect of IT on durability has been hypothesized:

$\mathrm{H}_{3}$ : IT adoption has significant positive effect on Durability.

Durdyeva et al. (2014) passed on verifiable examination and the results focuses on the subjective perspective of customers on effectiveness and saw advantage quality. Eventual outcome of this examination, develops a system and a movement prepare for administering productivity and saw advantage quality. Thus, it can be hypothesized as follows:

$\mathrm{H}_{4}$ : IT adoption has significant positive effect on Serviceability.

\section{Methodology}

A questionnaire in the form of a survey instrument was developed using the total design method (Jun \& Cai, 2010). Survey items were collected from previously published studies. The objective of questionnaire was to elicit the opinion of the respondents on the importance of the need and effectiveness related factors (Vera \& Trujillo, 2013). The questionnaire at the initial stage was sent to selected persons for pretesting. Pilot test was done for survey instrument and selected persons were included (Table 1). Modifications were made wherever necessary and unreliable items were eliminated where ten subject matter experts conducted a Q-sort analysis (Hussain \& Gunasekaran, 2002). Then, the final version of the questionnaire was designed. A database was created by selecting all leading service industries. The sample firms defined in the database are randomly selected. 
Table 1

Distribution and Composition of Panelists

\begin{tabular}{ccc}
\hline Category & No. of persons contacted & No. of respondents \\
\hline Executives from Industry & 30 & 19 \\
Professors and Researchers & 18 & 11 \\
\hline Total & 48 & 30 \\
\hline
\end{tabular}

\subsection{Survey Design}

The target population for this research was selected from Indian Bank and IT firms. By using the nonprobability sampling technique, a scientific stratified sampling scheme was implemented. The research analysis was from a single branch or unit. The respondents were related with IT activities. In 2015, managers from various departments in the banking and software firm with IT expertise whose standard Industrial classification codes were 7371 (software firms) and 6021 (Nationalized commercial Banks) were included as respondent titles. Stratified sampling has several potential benefits (Carmeli et al., 2008). 125 completed surveys were returned from 500 surveys that were mailed, with a response rate of 25 percent. Units having 51 to 100 employees corresponds $40 \%$, between 101- 200 employees $30 \%$, and more than 200 employees rest $30 \%$. Banking (48 percent) and IT firms (52 percent) were the respondents from the sample. ANOVA (analysis of variance) was carried out across the two service sectors and non-response bias was assessed by comparing general characteristics of non-responding firms (Therrien et al., 2011). No differences were detected. Table 2 represents frequency distribution of responding firms.

Table 2

Frequency distribution of responding firms

\begin{tabular}{cccc}
\hline SIC Code & Firms Approached & Responses Received & Percentage \\
\hline SIC 6021 & 300 & 60 & 48 \\
SIC 7371 & 200 & 65 & 52 \\
\hline Total & 500 & 125 & 100 \\
\hline
\end{tabular}

\subsection{Dependent variables}

A set of variables were considered to measure quality of service system. Reliability, conformance, durability and serviceability are taken as functions of service quality. Reliability, conformance, durability and serviceability are described in Table 3.

Table 3

Variables used to measure service quality

\begin{tabular}{clll}
\hline \multicolumn{1}{c}{ Reliability } & \multicolumn{2}{l}{ Durability } \\
\hline i & Employees Never linger guests & i & Internal decoration \\
ii & Bank tries to minimize all delays & ii & External bank region \\
iii & The hotel keeps records accurately & iii & Bank is outfitted with modern and easy to use equipment \\
iv & All materials needed to provide services are enough & iv & Equipment works well without any breakdown \\
v & Employees always treat politely especially when quests complain & v & Public areas are quite clean \\
vi & Bank services scheduling is flexible and proportionate to guests & vi & Internet facility \\
\hline Conformance & & Serviceability \\
\hline i & Employees notice to guests before they require & i & Employees seem young \\
ii & Employees try to provide pleasant experience by heart & ii & Employees are willing to solve guests' problems \\
iii & Employees give individualized attention to guests & iii & Employees know when and how services provide \\
iv & The Bank l's services are in accordance with guests' needs and desire & iv & Employees listen to customers' requests with patience \\
v & Employees understand customers' specific needs rapidly & v & Guests can easily express their criticism \\
\hline
\end{tabular}

\subsection{Independent variables}

Survey items of IT adoption to measure system performance are presented in Table 4. Fig. 1 shows the ANN model relating input parameters (tenure of IT adoption, utility of IT adoption, and vendor support for IT adoption) and output parameters (Reliability, conformance, durability and serviceability) for service system performance. There exists one hidden layer in the model. 
Table 4

Variables used for IT usage

\begin{tabular}{|c|c|}
\hline \multicolumn{2}{|r|}{ Tenure of IT Adoption } \\
\hline $\mathrm{i}$ & usage $<2$ years \\
\hline ii & usage between $03-05$ years \\
\hline iii & usage between $06-10$ years \\
\hline iv & usage $>10$ years \\
\hline \multicolumn{2}{|r|}{ Percentage of IT Utilization } \\
\hline $\mathrm{i}$ & utilization $<25 \%$ \\
\hline ii & utilization between $26-50 \%$ \\
\hline iii & utilization between $51-75 \%$ \\
\hline iv & utilization between $76-100 \%$ \\
\hline \multicolumn{2}{|r|}{ Percentage of IT Adoption Developed by Vendors } \\
\hline $\mathrm{i}$ & adoption $<25 \%$ \\
\hline ii & adoption between $26-50 \%$ \\
\hline iii & adoption between $51-75 \%$ \\
\hline iv & adoption between $76-100 \%$ \\
\hline
\end{tabular}

\subsection{Control variables}

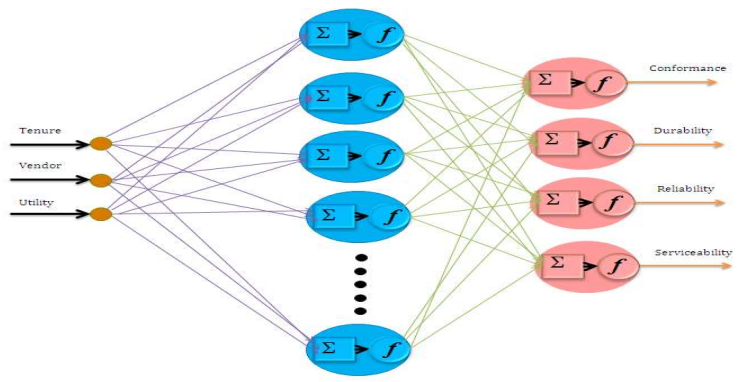

Fig. 1. ANN model for relating IT adoption and service quality

\section{Analysis of Results}

Based on the optimal validation performance, training $\mathrm{R}$ and validation $\mathrm{R}$ values, different process parameters are chosen and documented. Based on the optimal parameter value, final model has been developed. Various values of neural network model which has been used in the final mapping of IT adoption and performance are provided in Table 5. Neural network modelling has been performed using MATLAB $2011 b$.

\section{Table 5}

Optimal process parameter setting of Feed Forward Neural Architecture (FFNA)

\begin{tabular}{|c|c|c|c|}
\hline $\begin{array}{l}\text { SI. } \\
\text { No. }\end{array}$ & Parameter & Data and its range & Technique and type of parameter used \\
\hline 01 & Neural architecture & - & FFNA \\
\hline 02 & Number of input neurons & 3 (tenure, utility and vendor) & - \\
\hline 03 & No. of output neurons & 3 (performance measures) & - \\
\hline 04 & Total no. of exemplars & 125 & - \\
\hline 05 & Number of hidden layer & 01 & - \\
\hline 06 & Ratio of training, validation and testing of data & $80: 10: 10$ & - \\
\hline 07 & Normalization of data & 0.05 to 0.95 & Min-max data normalization technique \\
\hline 08 & Initialization of weight & -0.5 to 0.5 & Random wt. initialization \\
\hline 09 & Transfer function/ Activation function & 0 and 1 for logsig and -1 to 1 for tansig & $\begin{array}{l}\text { Logsig for hidden Layer \& tansig for out- } \\
\text { put Layer }\end{array}$ \\
\hline 10 & Error function & - & Mean squared error function \\
\hline 11 & Training Algorithm & - & $\begin{array}{l}\text { Levenberg-Marquardt back propagation } \\
\text { type }\end{array}$ \\
\hline 12 & Mode of training & - & Batch mode \\
\hline 13 & Type of learning rule & - & Supervised learning rule \\
\hline 14 & Stopping criteria & - & Early stopping \\
\hline
\end{tabular}




\subsection{Choosing number of hidden Layer and transfer function / activation function:}

To select the best hidden layer and transfer/activation function, ANN modelling was performed for performance measures. Several variations of FFNA have been considered and documented in Table 6:

Table 6

Variation of Process Parameters of Feed Forward Neural Architecture (FFNA)

\begin{tabular}{cccc}
\hline Sl. No. & Parameters & Type of parameter & Data or range of data \\
\hline 01 & Hidden layer & NA & $1,2,3$ \\
02 & Hidden Neuron & NA & 8,16 \\
03 & Transfer function/ Activation function & Tansig, logsig, purelin \& hardlim & NA \\
\hline
\end{tabular}

Based upon the values of optimal validation quality, training $\mathrm{R}$ and validation $\mathrm{R}$, different process parameters for ANN model was obtained. It was found that FFNA performs better than Elman and Layer Recurrent models. In the sub sections below, effect of IT adoption upon various performance measures (Reliability, conformance, durability and serviceability) are discussed:

\section{Case - 1: Reliability}

Effect of tenure of IT adoption, utility of IT and vendor contribution upon Reliability of quality was carried out. Table 7 shows the process parameter setting and Evaluation parameters of Neural Architecture i.e., Validation performance, Training $\mathrm{R}$ and Validation $\mathrm{R}$. it is observed that single hidden layer provides the optimum results rather than multiple layers.

Fig. 2 and Fig. 3 show the Main Effects Plot for Validation quality and Main Effects Plot for Training R respectively.

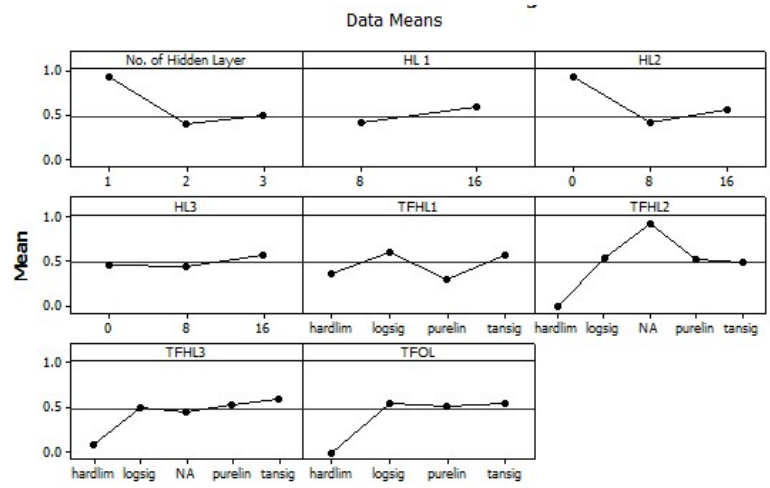

Fig. 2. Main Effects Plot for Validation Performance
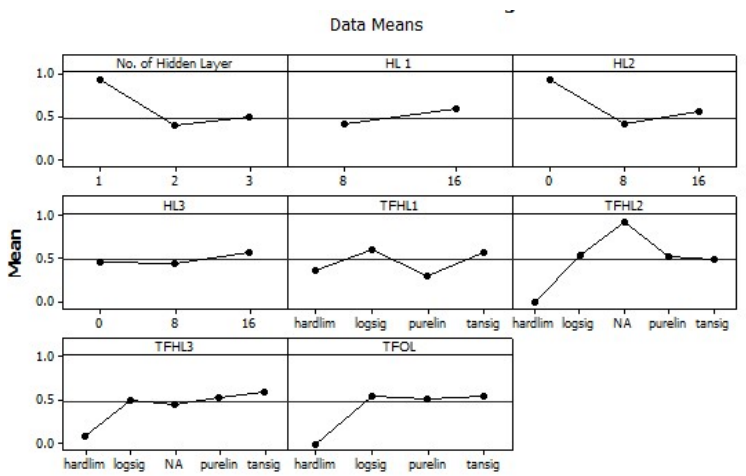

Fig. 3. Main Effects Plot for Training R

Using statistical methods and SPSS software, data collected from questionnaire have been analyzed. The effect of IT on service quality was checked. Using confidence level of $95 \%$ (significance level of $\alpha=0.05$ ), the analysis of variance (ANOVA) was carried out. Tenure of IT adoption, utility of IT and vendor contribution upon reliability of service quality has been modeled. Results obtained from ANOVA have been verified with that of ANN modeling. Reliability linearly increases with tenure and utility (Fig. 4 (a), 4 (b)). However, vendor does not have significant effect on quality (Fig. 4 (c)).

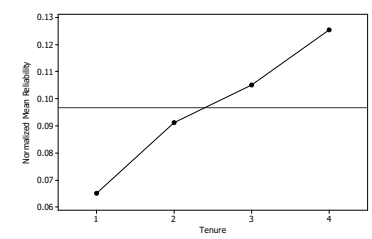

Fig. 4 (a). Tenure vs. Reliability

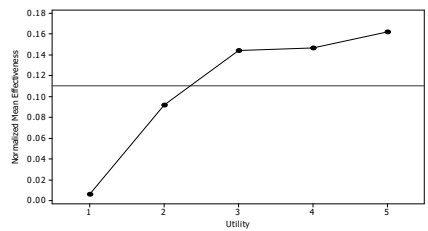

Fig. 4 (b). Utility vs. Reliability

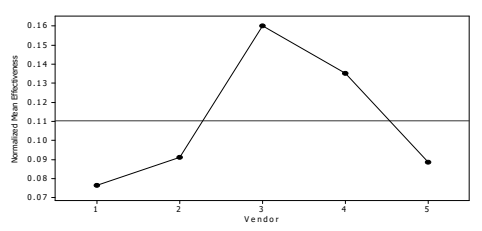

Fig. 4 (c). Vendor developed IT service vs. Reliability 
Table 7

FFNA modelling of Reliability

\begin{tabular}{|c|c|c|c|c|c|c|c|c|c|c|}
\hline \multirow{2}{*}{$\begin{array}{l}\text { No. of } \\
\text { Hidden } \\
\text { Layer }\end{array}$} & \multicolumn{3}{|c|}{ No. of Hidden Neurons } & \multicolumn{4}{|c|}{ Name of the Transfer function } & \multicolumn{3}{|c|}{ Evaluation of Neural Architecture } \\
\hline & HL 1 & HL2 & HL3 & HL1 & HL2 & HL3 & Output Layer & $\begin{array}{l}\text { Validation Perfor- } \\
\text { mance }\end{array}$ & Training $\mathrm{R}$ & Validation $\mathrm{R}$ \\
\hline 1 & 16 & 0 & 0 & logsig & NA & NA & tansig & 0.0036601 & 0.934860 & 0.769840 \\
\hline 2 & 8 & 8 & 0 & logsig & tansig & NA & tansig & 0.0039148 & 0.284740 & 0.433360 \\
\hline 2 & 8 & 8 & 0 & logsig & logsig & NA & logsig & 0.0055465 & 0.760420 & 0.743690 \\
\hline 2 & 8 & 8 & 0 & tansig & tansig & NA & tansig & 0.0051059 & 0.369710 & 0.440370 \\
\hline 2 & 8 & 8 & 0 & tansig & logsig & NA & logsig & 0.0041813 & 0.675000 & 0.649440 \\
\hline 2 & 8 & 8 & 0 & purelin & purelin & NA & purelin & 0.0075013 & 0.265770 & 0.224810 \\
\hline 2 & 8 & 8 & 0 & logsig & purelin & NA & purelin & 0.0028377 & 0.801810 & 0.806020 \\
\hline 2 & 8 & 8 & 0 & tansig & purelin & NA & purelin & 0.0045189 & 0.526430 & 0.450190 \\
\hline 2 & 8 & 8 & 0 & hardlim & hardlim & NA & hardlim & 0.0367430 & -0.22350 & 0.000001 \\
\hline 2 & 8 & 8 & 0 & hardlim & logsig & NA & logsig & 0.0071636 & 0.426930 & 0.449550 \\
\hline 2 & 8 & 8 & 0 & hardlim & tansig & NA & tansig & 0.0039731 & 0.205970 & 0.799190 \\
\hline 2 & 8 & 8 & 0 & hardlim & purelin & NA & purelin & 0.0037370 & 0.403280 & 0.247730 \\
\hline 3 & 8 & 8 & 8 & logsig & tansig & tansig & tansig & 0.0150130 & 0.385050 & 0.045124 \\
\hline 3 & 8 & 8 & 8 & logsig & logsig & logsig & logsig & 0.0042006 & 0.635720 & 0.414520 \\
\hline 3 & 8 & 8 & 8 & tansig & tansig & tansig & tansig & 0.0102870 & 0.388770 & -0.45102 \\
\hline 3 & 8 & 8 & 8 & tansig & logsig & logsig & logsig & 0.0051147 & 0.633870 & 0.246040 \\
\hline 3 & 8 & 8 & 8 & purelin & purelin & purelin & purelin & 0.0068376 & 0.322350 & 0.306700 \\
\hline 3 & 8 & 8 & 8 & logsig & purelin & purelin & purelin & 0.0081982 & 0.546680 & 0.677770 \\
\hline 3 & 8 & 8 & 8 & tansig & purelin & purelin & purelin & 0.0195960 & 0.590540 & -0.08440 \\
\hline 3 & 8 & 8 & 8 & hardlim & hardlim & hardlim & hardlim & 0.0336730 & 0.099755 & -0.38109 \\
\hline 3 & 8 & 8 & 8 & hardlim & logsig & logsig & logsig & 0.0075966 & 0.303570 & 0.044888 \\
\hline 3 & 8 & 8 & 8 & hardlim & tansig & tansig & tansig & 0.0120870 & 0.570750 & 0.540470 \\
\hline 3 & 8 & 8 & 8 & hardlim & purelin & purelin & purelin & 0.0071053 & 0.326870 & 0.257110 \\
\hline 3 & 16 & 16 & 16 & logsig & tansig & tansig & tansig & 0.0085248 & 0.610430 & 0.181060 \\
\hline 3 & 16 & 16 & 16 & logsig & logsig & logsig & logsig & 0.0067315 & 0.393390 & 0.563910 \\
\hline 3 & 16 & 16 & 16 & tansig & tansig & tansig & tansig & 0.0048325 & 0.849490 & 0.708520 \\
\hline 3 & 16 & 16 & 16 & tansig & logsig & logsig & logsig & 0.0046065 & 0.267190 & 0.534970 \\
\hline 3 & 16 & 16 & 16 & purelin & purelin & purelin & purelin & 0.0066916 & 0.308290 & 0.052770 \\
\hline 3 & 16 & 16 & 16 & logsig & purelin & purelin & purelin & 0.0031567 & 0.714040 & 0.535260 \\
\hline 3 & 16 & 16 & 16 & tansig & purelin & purelin & purelin & 0.0038985 & 0.878170 & 0.577420 \\
\hline 3 & 16 & 16 & 16 & hardlim & hardlim & hardlim & hardlim & 0.0327400 & 0.057672 & -0.39829 \\
\hline 3 & 16 & 16 & 16 & hardlim & logsig & logsig & logsig & 0.0045414 & 0.773530 & 0.662770 \\
\hline 3 & 16 & 16 & 16 & hardlim & tansig & tansig & tansig & 0.0100670 & 0.789300 & -0.28316 \\
\hline 3 & 16 & 16 & 16 & hardlim & purelin & purelin & purelin & 0.0103420 & 0.575690 & 0.003932 \\
\hline
\end{tabular}

\section{Case - 2: Conformance}

Process parameter setting and evaluation parameters (Validation Performance, Training $\mathrm{R}$ and Validation R) have been obtained using FFNA modeling, as in Table 7. Fig. 5 and Fig. 6 show the Main Effects Plot for Training R and Main Effects Plot for Validation Performance respectively.

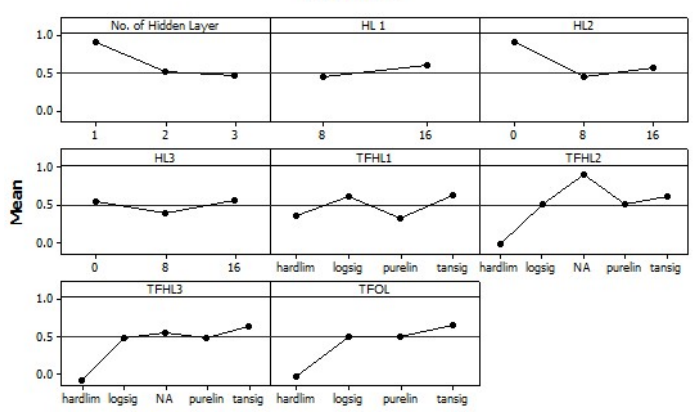

Fig. 5. Main Effects Plot for Training R

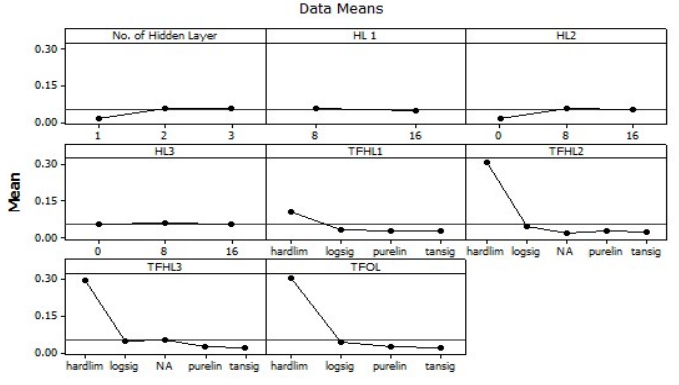

Fig. 6. Main Effects Plot for Validation Performance

Tenure of IT adoption, utility of IT and vendor contribution upon efficiency has been modeled. Results obtained from ANN model have been verified with that of ANOVA. Conformance increases with increase in tenure and utility of IT service (Figs. 7 (a), (b)). However, vendor plays no role (Fig. 7 (c)). Thus, more the IT service being utilized, more will be the firm's Conformance. 


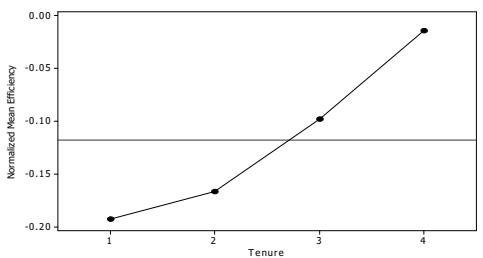

Fig. 7. (a). Tenure vs. Conformance

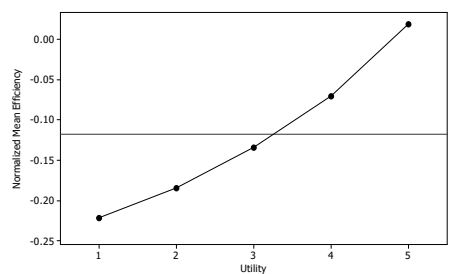

Fig. 7 (b). Utility vs. Conformance

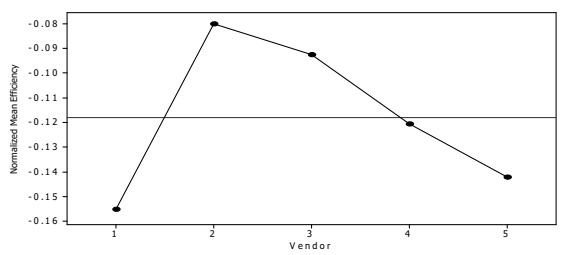

Fig. 7 (c). Vendor developed IT service vs. Conformance

\section{Case - 3: Durability}

Using FFNA modeling, Validation Performance, Training R and Validation R values for process parameter setting and evaluation parameters have been obtained, as in Table 7. Fig. 8 and Fig. 9 show the Main Effects Plot for Training R and Validation Performance respectively.

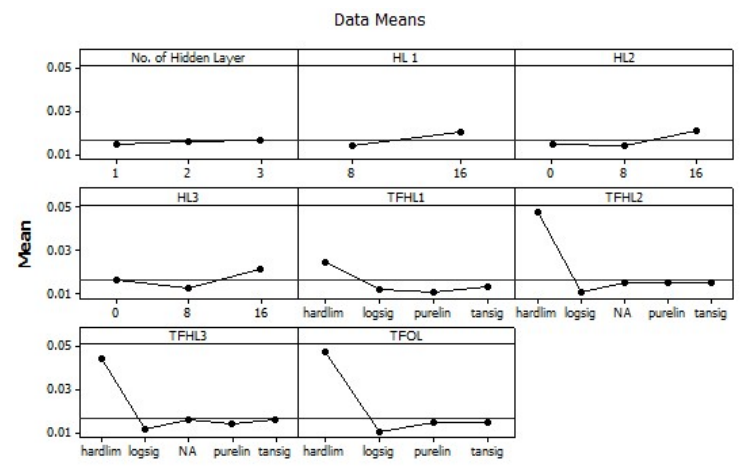

Fig. 8. Main Effects Plot for Training R

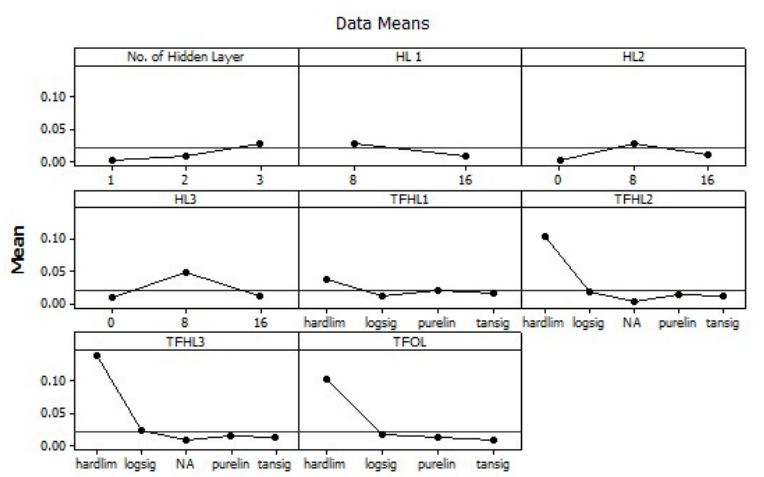

Fig. 9. Main Effects Plot for Validation Performance

Tenure of IT adoption, utility of IT and vendor contribution upon durability improvement of firm has been modeled. Results obtained from statistical analysis using ANOVA have been verified with that of ANN model. Durability increases with tenure (Fig. 10 (a)) and utility (Fig. 10 (b)). Vendor does not have any significant role for enhancing the durability of system (Fig. 10 (c)).

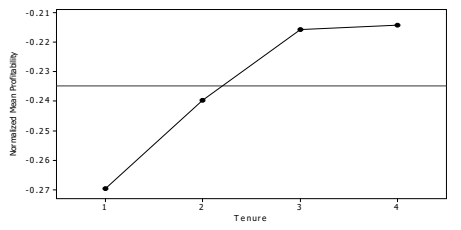

Fig. 10 (a). Tenure vs. Durability

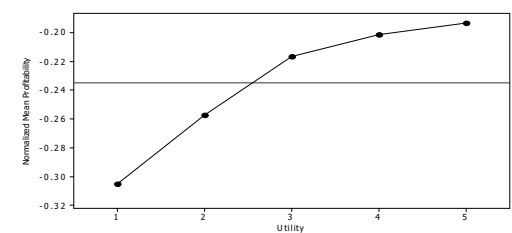

Fig. 10 (b). Utility vs. Durability

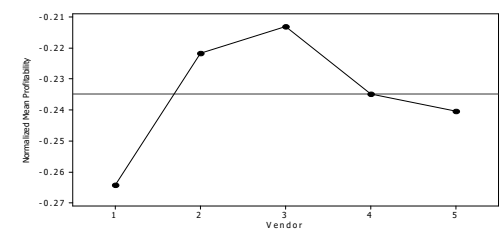

Fig. 10 (c). Vendor developed IT service vs. Durability

\section{Case - 4: Serviceability}

Using FFNA modeling, Validation Performance, Training R and Validation R values for process parameter setting and evaluation parameters have been obtained, as in Table 7. Fig. 11 and Fig. 12 show the Main Effects Plot for Training R and Validation Performance respectively. 


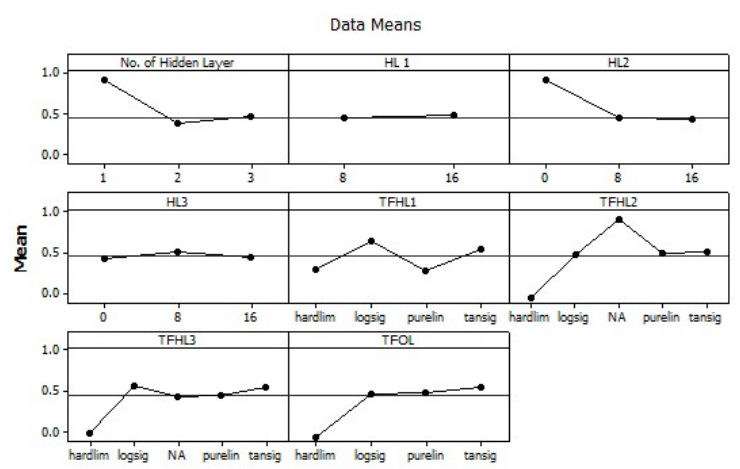

Fig. 11. Main Effects Plot for Training R

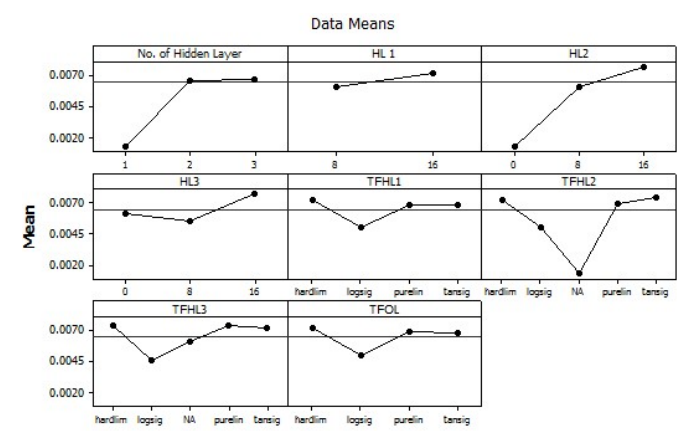

Fig. 12. Main Effects Plot for Validation Performance

Tenure of IT adoption, utility of IT and vendor contribution upon serviceability improvement of firm has been modeled. Results obtained from statistical analysis using ANOVA have been verified with that of ANN model. Serviceability increases with tenure (Fig. 13 (a)) and utility (Fig. 13 (b)). Vendor does not have any significant role for enhancing the serviceability of system (Fig. 13 (c)).

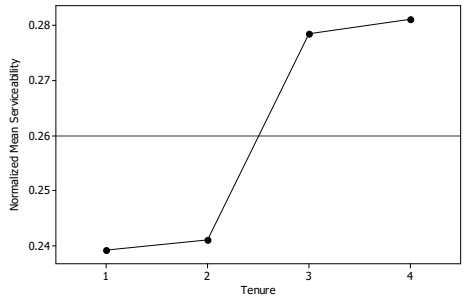

Fig.-13(a). Tenure vs. Serviceability

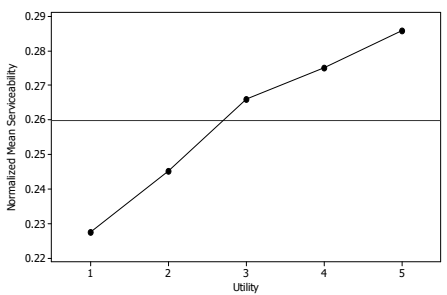

Fig.-13(b). Utility vs. Serviceability

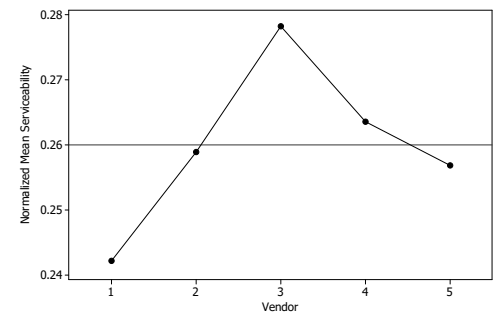

Fig.-13(c). Vendor vs. Serviceability

\section{Conclusions and Recommendations for Future Research}

Normal probability plot for Reliability, conformance, durability and serviceability were drawn for residuals. It confirms the normal distribution of the data as the graph approaches linearity. Relationship between predicted values and standardized residuals were also checked. It has been observed that, data were distributed in both positive and negative directions and concluded that the model was adequate having no cause to think about violation of the constant variance assumption or independence. Histogram for all the above cases were drawn and all reflects uniform distribution around ' 0 ' (mean value) and shows conformance of the constant variance of the entire data, plotted between standard residual and observation order. After analyzing the result of Training R and Validation Performance from the obtained Main Effect Plots and the tabulated results of various FFNA modelling for all the performance measures, it can be concluded that the process parameter setting of FFNA (transfer function, number of hidden layer, number of hidden neurons) that has been tabulated in Table 5 is optimal. With the help of specified process parameters in the above table, final neural network model has been developed. With varying hidden layers and learning parameter, the following observations were made:

i) Changing the hidden layers and also the learning parameter there will be a variation in performance of ANN model, and the same has been demonstrated. It is concluded that single hidden layer with 16 numbers of neuron gives the best result for quality.

ii) The appropriate transfer function found from above analysis for hidden layer is logsig and for output layer is tansig, which has been implemented in the final model. 
iii) In neural network modelling, increasing the inputs will have impact. In this research, the number of input variable remains same for all the quality measures.

Quality of ANN model is mainly dependent upon the type of neural architecture, number of hidden neurons, number of hidden layers, and type of transfer/activation function. In order to build up an efficient ANN model, the focus has been given on the above critical parameters. However, increasing the number of outputs in network, will not affect the quality of the developed ANN model as the modelling has been done with optimal process parameter setting.

\subsection{Bivariate Correlations}

In order to examine the bivariate relationship, scatter plots have been formed. It has been observed that the corresponding joint values of the variables lie along a straight line, thus a linear relationship or correlation exists. No combination seems to exhibit a non linear relationship that would not be represented in a bivariate correlation.

\subsection{Testing the Hypotheses}

The model developed for establishing relationship between IT adoption and quality is applied in banks as well as software firms. Both the input variable tenure and utility bears significant positive relationship with service quality. However, vendor bears no relationship with quality. The application of the methodology has been found to result in better understanding than that of the existing methodologies relating IT adoption - service quality.

\subsection{Directions for Future Research}

Author identifies the following few important areas, that need further study: (i) consideration of other 'intangible' factors, (ii) Contribution of resources, effect of intellectual apathy, leadership quality, (iii) Other services such as, hospital, hotel, airline, education may be taken into account, and (iv) Development of suitable IT adoption and evaluation model for production firms.

\section{References}

Arasli, H. (2005). A comparison of service quality in the banking industry: Some evidence from Turkish and Greek-speaking areas in Cyprus. International Journal of Bank Marketing, 23(7), 508-526.

Behera, A, Nayak N.C., \& Das, H. (2015a). Performance measurement in Banking \& Software firm: an empirical research. Global Journal of Flexible Systems Management, 16(1), 3-18.

Behera, A, Nayak N.C., \& Das, H. (2015b). An empirical study of the impact of IT on performance in service Industries. Global Business and Organizational Excellence, 34(3), 67-78.

Behera, A.K., Nayak, N.C., \& Das, H.C. (2015c). Performance measurement due to IT adoption. Business Process Management Journal, 21(4), 888-907.

Bergendahl, G. \& Lindblom, T. (2008). Evaluating the performance of Swedish savings banks according to service efficiency. European Journal of Operational Research, 185, 1663-1673.

Bruque, S., \& Moyano, J. (2007). Organisational determinants of information technology adoption and implementation in SMEs: The case of family and cooperative firms. Technovation, 27(5), 241-253.

Carmeli, A., Sternberg, A., \& Elizur, D. (2008). Organizational culture, creative behavior, and information and communication technology (ICT) usage: A facet analysis, Cyber Psychology and Behavior, 11(2),175-180.

Chan, H. C. Y., \& Ngai, E. W. T. (2010). What Makes Customers Discontent with Service Providers? An Empirical vice Analysis of Complaint Handling in Information and Communication Technology Services. Journal of Business Ethics, 91, 73-110. 
Chang, T.H (2014). Fuzzy VIKOR method: A case study of the hospital service evaluation in Taiwan. Information Sciences, 271, 196-212.

Chen, J.S., Tsou, M., \& Hung, T. (2012). Performance effects of IT capability, service process innovation, and the mediating role of customer service. Journal of Engineering Technology Management, 29, 71-94.

Cui, C.C., Lewis, B.R., \& Park, W. (2003). Service quality in the banking sector in South Korea. International Journal of Bank Marketing, 21(4), 191-201.

Davis, F.D. (1989). Perceived usefulness, perceived ease of use, and user acceptance of information technologies. MIS Quarterly, 13(3), 319-340.

Dewhurst, F.W., Lorente, A.R.M., \& Rodriguez, C.S. (2003). An initial assessment of the influence of IT on TQM: a multiple case study. International Journal of Operations \& Production Management, 23(4), 348-374.

Doha, R., Salimath, M., \& D’Souza, D. (2014). Disaster immunity and performance of service firms: The influence of market acuity and supply network partnering. International Journal of Production Economics, 147, 385-397.

Durdyeva, S., Ihtiyar, A., Syuhaida I. S., Ahmad, F.S., \& Bakare, N.A. (2014). Productivity and service quality: Factors affecting in service industry. Procedia - Social and Behavioral Sciences, 109, 487491.

Ghobakhloo, M., Zulkifli, N.B., \& Aziz, F.A. (2010). The interactive model of User information technology acceptance and satisfaction in small and medium-sized enterprises. European Journal of Economics, Finance and Administrative Sciences, 19(1), 7-27.

Ghobakhloo, M., Benitez-Amado, J., \& Arias-Aranda, D. (2011). Reasons for information technology adoption and sophistication within manufacturing SMEs. Paper presented at the POMS 22nd Annual Conference: Operations management, Reno, USA, April 29 to May 2.

Goo, J. (2010). Structure of service level agreements (SLA) in IT outsourcing: The construct and its measurement. Information System Front, 12, 185-205.

Gustafsson, A., Nilsson, L., \& Johnson, M.D. (2003). The role of quality practices in service organizations. International Journal of Service Industry Management, 14(2), pp.232-244.

Al-Hawari, M., \& Ward, T. (2006). The effect of automated service quality on Australian banks' financial performance and the mediating role of customer satisfaction. Marketing Intelligence \& Planning, 24(2), 127-147.

Hussain, M.M., \& Gunasekaran, A. (2002). Management accounting and performance measures in Japanese banks. Managing Service Quality, 12(4), 232-245.

Igbaria, M., \& Tan, M. (1997). The consequences of information technology acceptance on subsequent individual performance. Information \& Management, 32(3), 113-121.

Jayawardhena, C. (2004). Measurement of service quality in internet banking: the development of an instrument. Journal of Marketing Management, 20(1-2), 185-207.

Jun, M., \& Cai, S. (2010). The key determinants of Internet bank service quality: A content analysis. International Journal of Bank Marketing, 19(7), 276-291.

Kannabiran, G., \& Narayan, P. (2005). Deploying Internet banking and e-commerce: case study of a private sector bank in India. Information Technology for Development, 11(4), 363-379.

KPMG (2015). Mobile banking (2015) https://www.kpmg.com/ UK/en/IssuesAndInsights/ Articles Publications/Documents/PDF/mobile-banking-report-2015.pdf.

Lepmets, M., Mesquida, A.L., Cater, S.A., Mas, A., \& Ras, E. (2014). The evaluation of the IT service quality measurement framework in industry. Global Journal of Flexible Systems Management, 15(1), 39-57.

Mwangi, B. J., \& Brown, I. (2015). A decision model of Kenyan SMEs' consumer choice behavior in relation to registration for a mobile banking service: A contextual perspective. Information Technology for Development, 21(2), 229-252.

Mikhailov, L., \& Tsvetinov, P. (2004). Evaluation of services using a fuzzy analytic hierarchy process. Applied Soft Computing, 5(1), 23-33. 
Parka, J., Leea, J., Leea, H., \& Truex, D. (2012). Exploring the impact of communication effectiveness on service quality, trust and relationship commitment in IT services. International Journal of Information Management, 32, 459-468.

Peter, K.C., Cheng, T.C.E., Yeung, A.C.L., \& Lai, K.H (2011). An empirical study of transformational leadership, team performance and service quality in retail banks. Omega, 39, 690-701.

Pick, J. B., Gollakota, K., \& Singh, M. (2013). Technology for development: Understanding influences on use of rural telecenters in India. Information Technology for Development, 20(4), 296-323.

Shaik, M.N., \& Abdul, K.W. (2014). Comprehensive performance measurement and causal-effect decision making model for reverse logistics enterprise. Computers and Industrial Engineering, 68, 87103.

Southern, A., \& Tilley, F. (2000). Small firms and information and communication technologies (ICTs): toward a typology of ICTs usage. New Technology, Work and Employment, 15(2), 138-154.

Tanriverdi, H. (2005). Information technology relatedness, knowledge management capability, and performance of multibusiness firms. MIS Quarterly, 29(2), 311-334.

Therrien, P., David, D., \& Tyler, C. (2011). Innovation novelty and (commercial) performance in the service sector: A Canadian firm-level analysis. Technovation, 31, 655-665.

Vera, J., \& Trujillo, A. (2013). Service quality dimensions and superior customer perceived value in retail banks: An empirical study on Mexican consumers. Journal of Retailing and Consumer Services, 20, 579-586.

Yan, L., Yingwu, C., \& Changfeng, Z. (2006). Determinants affecting end-user satisfaction of information technology service. Paper presented at the Proceedings - ICSSSM'06: International Conference on Service Systems and Service Management.

Yee, R. W.Y, Lee, P.K.C., Yeung, A. C.L., \& Cheng, T.C.E. (2013). The relationships among leadership, goal orientation, and service quality in high-contact service industries: An empirical study. International Journal of Production Economics, 141, 452-464.

Zhang, X., Chen, R., \& Ma, Y. (2007). An empirical examination of response time, product variety, and firm performance. International Journal of Production Research, 45(14), 3135-3150.

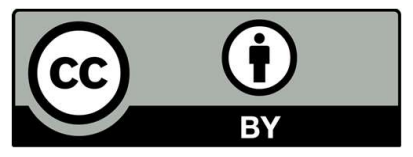

(C) 2020 by the authors; licensee Growing Science, Canada. This is an open access article distributed under the terms and conditions of the Creative Commons Attribution (CC-BY) license (http://creativecommons.org/licenses/by/4.0/). 